\title{
Early hematopoietic and vascular development in the chick
}

\author{
HIROKI NAGAI ${ }^{1,5}$, MASAHIRO SHIN2,5, WEI WENG ${ }^{1,5}$, FUMIE NAKAZAWA ${ }^{5}$, LARS MARTIN JAKT ${ }^{3,5}$, \\ CANTAS ALEV ${ }^{4,5}$ and GUOJUN SHENG ${ }^{*, 1,5}$ \\ 'International Research Center for Medical Sciences (IRCMS), Kumamoto University, Kumamoto, Japan, \\ ${ }^{2}$ University of Massachusetts Medical School, Worcester, Massachusetts, USA, ${ }^{3}$ Faculty of Biosciences and \\ Aquaculture, Nord University, Bodo, Norway, ${ }^{4}$ Center for iPS Cell Research and Application (CiRA), Kyoto University, \\ Kyoto, Japan and ${ }^{5}$ RIKEN Center for Developmental Biology, Kobe, Japan
}

\begin{abstract}
The field of hematopoietic and vascular developmental research owes its origin to the chick embryo. Many key concepts, such as the hematopoietic stem cell, hemangioblast and hemogenic endothelium, were first proposed in this model organism. Genetically tractable models have gradually replaced the chick in the past two decades. However, advances in comparative genomics, transcriptomics and promoteromics promise a re-emergence of the chick embryo as a powerful model for hematopoietic/vascular research. This review summarizes the current status of our understanding of early blood/vascular development in the chick, focusing primarily on the processes of primitive hematopoiesis and early vascular network formation in the extraembryonic and lateral plate mesoderm territories. Emphasis is given to ontological and molecular association between the blood and endothelial cells and to the evolutionary relationship between the hemangioblasts, common precursors for the blood and endothelial lineages, and the coelomic epithelial lining cells. Links between early blood/vascular development and later definitive hematopoiesis are also discussed. Finally, potential applications of the chick model for comparative and omics-level studies of the blood/vascular system are highlighted.
\end{abstract}

KEY WORDS: remodeling, evolution, vascular smooth muscle, transcriptome, promoterome

\section{Overview of chicken primitive hematopoietic development before circulation}

The chicken blood/vascular system is composed of the blood, vascular endothelial and vascular smooth muscle cells, and the heart. All blood cells are of the lateral plate or extraembryonic mesoderm origin, as are the majority of the endothelial and vascular smooth muscle cells (Sheng, 2010). The heart is an integral part of the blood/vascular system, with both the endocardium and myocardium derived from the lateral plate mesoderm (Martinsen, 2005). But as there have been many specialized reviews on this organ, the heart will not be discussed further in this review. The origins of the blood, endothelial and vascular smooth muscle cells are tightly linked during early chick development (Nakazawa et al., 2006, Shin et al., 2009). All three cell types are derived from ventral mesoderm precursors, located roughly in the posterior half of the primitive streak at stage $\mathrm{HH} 4$ (Hamburger and Hamilton stage 4), which will give rise to both the extraembryonic mesoderm and intraembryonic lateral plate mesoderm cell lineages (Alev et al., 2010b, Psychoyos and Stern, 1996). Dorsoventral patterning of the mesoderm precursors, reflected in their anterior-posterior locations along the primitive streak, are regulated by a combination of signaling gradients in the primitive streak, including those of the BMP, FGF and Wnt pathways (Alev et al., 2010b). Ventral mesoderm precursor cells leave the epithelial-shape epiblast by undergoing epithelial to mesenchymal transition in the primitive streak (Fig.1 top-left panel), as with other mesoderm cell types, and migrate away from the primitive streak to populate peripheral territories of the embryo (Nakaya and Sheng, 2009, Nakaya et al., 2013, Psychoyos and Stern, 1996, Yang et al., 2008).

From stage $\mathrm{HH} 5$ to stage $\mathrm{HH} 7$, during their active migration and before reaching their final destinations, ventral mesoderm cells are segregated into two cell types by mutual inhibition (Fig.1, top-right panel), the hemangioblasts expressing markers such as $\mathrm{Scl}$ and

Abbreviations used in this paper: $\mathrm{HH}$, Hamburger and Hamilton developmental stage.

\footnotetext{
*Address correspondence to: Guojun Sheng. 2-2-1 Honjo, Chuo-ku, Kumamoto 860-0811, Japan. Tel: 81-96-373-6874. E-mail: sheng @ kumamoto-u.ac.jp (iD) http://orcid.org/0000-0001-6759-3785
}

Supplementary Material (table) for this paper is available at: http://dx.doi.org/10.1387/ijdb.170291gs

Submitted: 1 November, 2017; Accepted: 9 November, 2017.

ISSN: Online 1696-3547, Print 0214-6282 

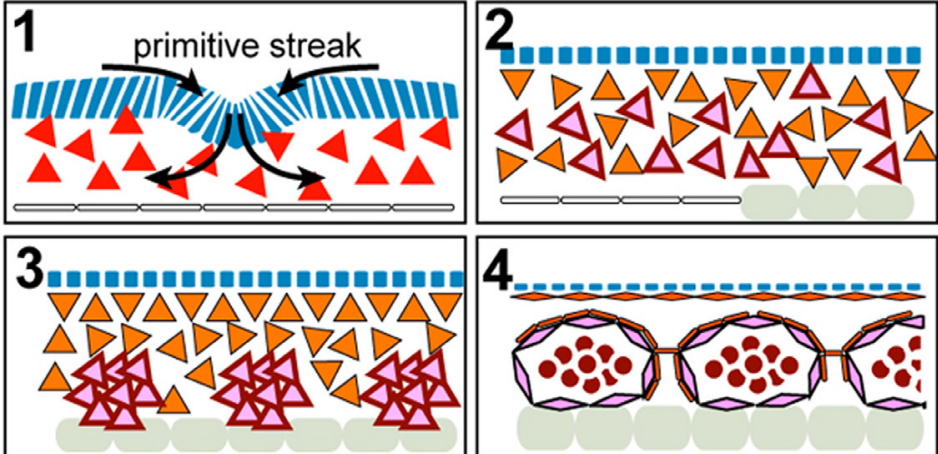

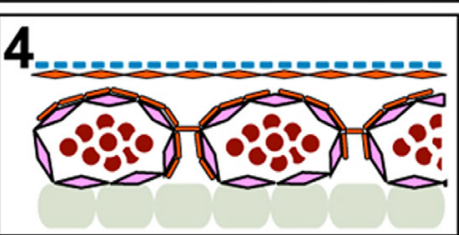

1: $\mathrm{HH} 4$

2: $\mathrm{HH} 5 / 6$

3: $\mathrm{HH} 7 / 8$

4: $\mathrm{HH} 9 / 10$

\section{Ectoderm \\ Smooth muscle \\ Endothelium \\ Blood \\ Endoderm}

Fig. 1. Cellular morphogenesis in early hematopoietic and vascular development. Lineage segregation events from stage HH4 to stage HH10. (1) Ventral mesoderm precursor cells located in and around the posterior primitive streak undergo epithelial-mesenchymal transition to become migratory mesoderm cells. (2) Hemangioblast precursors (pink triangle) and mesothelial (smooth muscle) precursors (orange triangle) sort out during migration. (3) Hemangioblast precursors coalesce to form blood islands. (4) Blood island cells differentiate into blood (red) and endothelial (pink) cells. Mesothelial (smooth muscle) cells split to form somatic mesothelium (underlying the ectoderm) and splanchnic mesothelium (covering vessels and endoderm). Reproduced from doi: 10.1242/dev.026906 with permission from The Company of Biologists.
Lmo2, and the smooth muscle progenitors (coelomic lining cells, mesothelial cells) expressing markers such as Hand2 (Shin et al., 2009). The hemangioblasts are bi-potential, common progenitors for the blood and vascular endothelial cell lineages (Nakazawa et al., 2006, Sheng, 2010, Weng et al., 2007). As a population, these progenitor cells generate both blood and endothelial lineages. But at the single cell-level, each hemangioblast rarely gives rise to both lineages in early chick development (Weng et al., 2007). The hemangioblasts aggregate during migration and each aggregate, varying in cell number, becomes one unit of blood island (Fig.1,

A
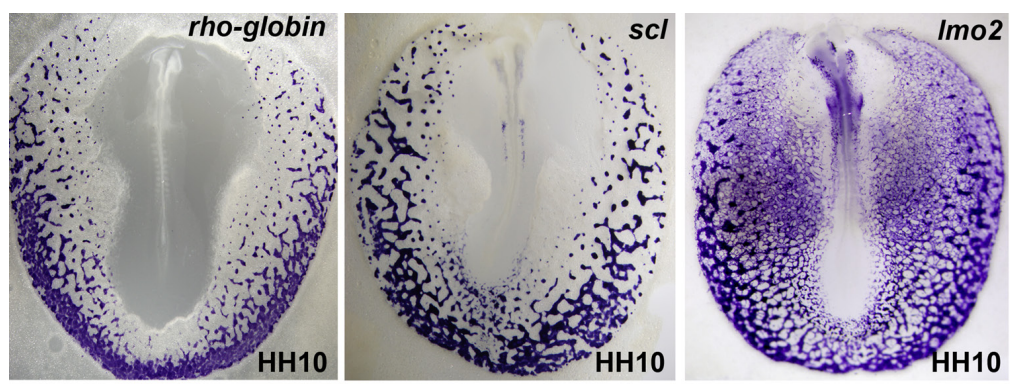

B
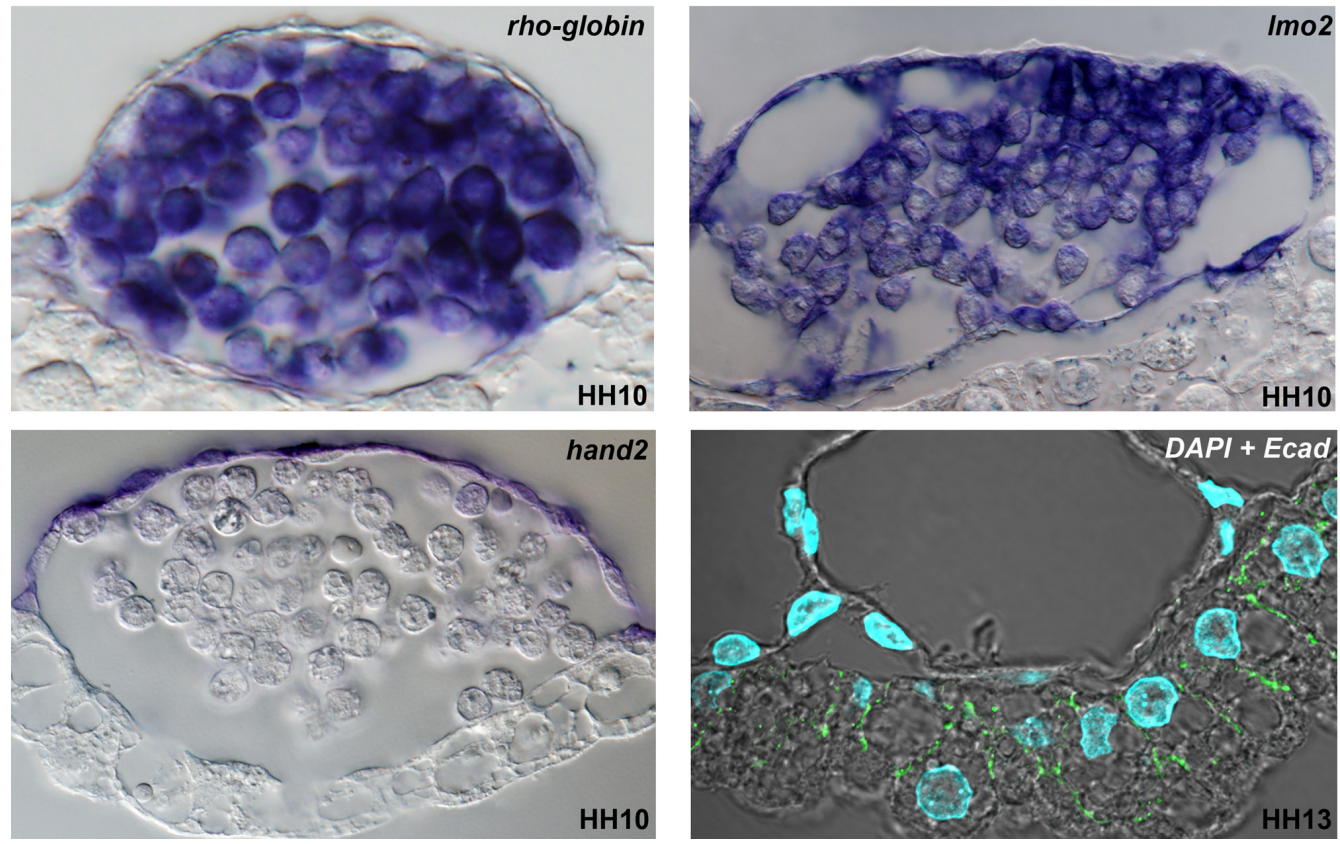

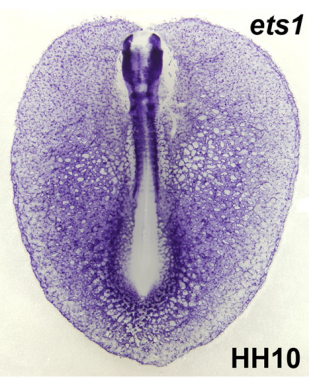

bottom-left panel). Peripherally located blood islands usually contain more cells, and percentage-wise more blood-fated cells are generated from peripheral blood islands than from the medial ones. At stage $\mathrm{HH} 7$, when cells in the blood islands are still morphologically indistinguishable, some of them start to express red blood cell (RBC) markers such as hemoglobins while the remaining cells in a given blood island will become endothelial cells (Nakazawa et al., 2006). Morphological changes in blood-fated and endothelialfated cells in blood islands soon follow at stages $\mathrm{HH} 8$ and $\mathrm{HH}$. Those relatively small blood islands located proximal to the embryo proper, including most of the blood islands in the embryonic lateral plate and in the proximal regions of the extraembryonic mesoderm, will not give rise to any blood cells; but instead they will undergo normal endothelial differentiation and morphogenesis, and serve to connect the endocardium of the developing

Fig. 2. Molecular specification in early hematopoietic and vascular development. (A) Expression patterns of rho globin (erythrocyte differentiation marker), scl (hemangioblastand hematopoietic marker), Imo2 (hemangioblast and vascular marker) and ets1 (hemangioblast and vascular marker) at stage $\mathrm{HH} 10$. (B) Magnified view of rho globin, Imo2, hand2 and Ecad expression Globin expression is restricted to the blood cells at stage HH1O. Imo2 marks both endothelial and blood cells at stage HH1O. hand2 is expressed in the smooth muscle lineage (mesothelium) at stage HH10. At stage HH13, blood cells start to circulate. The relationship between the vascular endothelial cells, vascular smooth muscle cells and endoderm cells is highlighted by DAPI (nuclei) and Ecad (endoderm adherens junction) staining. 
heart with the extraembryonic vascular network.

By stage $\mathrm{HH} 10$, a primitive vascular plexus and loss of cell-cell contact among blood cells can be identified through molecular marker analysis (Fig. 1, bottom-right panel; Fig. 2 A,B). At this point, expression of $\mathrm{Scl}$ (an early hemangioblast marker and later hematopoietic marker) starts to be limited to the blood lineage (Fig. 2A), while Lmo2 (an early hemangioblast marker and later vascular marker) still marks both the blood and endothelial lineages (Fig. $2 \mathrm{~A}, \mathrm{~B}$ ). At stage $\mathrm{HH} 12-13$, when the heart starts to function, a patent vascular system is already in place, and a majority of the blood cells have lost cell-cell contacts and can now circulate freely (Fig. 2B). The mesothelial precursors, those ventral mesoderm cells which do not express hemangioblast markers, will split and epithelialize into two layers, with their apical surface facing each other and creating the coelomic (or extraembryonic coelomic) cavity between them (Shin et al., 2009) (Fig. 1, bottom panels). In the embryo proper, the upper layer, the somatic mesothelial cells, will line the ectoderm and give rise to the mesoderm components of skin and appendages in later development. The somatic mesothelial cells in the extraembryonic territories will form the mesoderm lining of the amnion and chorion. The lower layer, the splanchnic mesothelial cells, will line the endoderm and surround the blood islands located in-between. The vascular smooth muscle cells are derived from those mesothelial cells. Both mesothelial layers express many common molecular markers, including Hand2 and SMA-alpha (Shin et al., 2009).

\section{Evolutionary perspective of hematopoietic and vascular development}

The overall developmental sequence and anatomical arrangement of the blood/vascular system outlined above are conserved among all amniote species. The relationship between the blood/ vascular system on one hand and the mesothelial cells on the other, however, has not received sufficient attention in developmental studies. It is worthwhile to take an evolutionary perspective and look at how the blood/vascular system evolved in coelomates (animals with mesothelial cell-lined coelomic cavity), which include all of the vertebrate species and most of the triploblastic invertebrates (Hartenstein, 2006). In both invertebrate and vertebrate coelomate species, a blood/vascular system is well-developed. However, many of the essential components of the vertebrate blood/vascular system, such as the RBCs and endothelial cells, are absent in most invertebrate coelomates. Their blood cells, called hemocytes, function mainly in host defense (e.g., in mediating phagocytosis, cytotoxicity and pathogen trapping). Hemocytes circulate either in exo-coelomic vascular channels (vascular circulation) or inside the coelomic cavity (coelomic circulation) (Hartenstein, 2006, Monahan-Earley et al., 2013, Munoz-Chapuli et al., 2005) (Fig. 3A). The vascular circulation lacks the endothelial lining as we know of in the vertebrates, and is instead confined by the extracellular matrix of the surrounding tissues (Hartenstein, 2006, Kucera et al., 2009, Monahan-Earley et al., 2013) (Fig. 3 A,B). The invertebrate hemocytes are considered to originate from the coelomic lining epithelium (Fig. 3B). The evolutionary origin of vertebrate endothelial cells is not clear. They have been hypothesized to come from a specialized hemocyte lineage with enhanced polarization capability and extracellular matrix affinity (Fig. $3 \mathrm{~B}, \mathrm{C}$ ). Although this theory awaits experimental support, an interesting evolutionary scenario is that the blood/vascular system formation in both invertebrate and vertebrate coelomates is tightly associated with the coelomic epithelium and that both the blood and the endothelial lineages in vertebrate animals share a common origin from the coelomic epithelium.

\section{Overview of chicken vascular development in the extraembryonic territory}

The earliest specification of the hemangioblasts (common precursors for the primitive blood and endothelial cells) takes place after the epithelial-mesenchymal transition of ventral mesoderm precursors at stage HH4 (Nakazawa et al., 2006, Shin etal., 2009). The earliest commitment of the blood lineage takes place at stage $\mathrm{HH}$ 7, marked by hemoglobin gene expression in erythropoietic cells in the blood islands. Therefore, vascular commitment in the chick

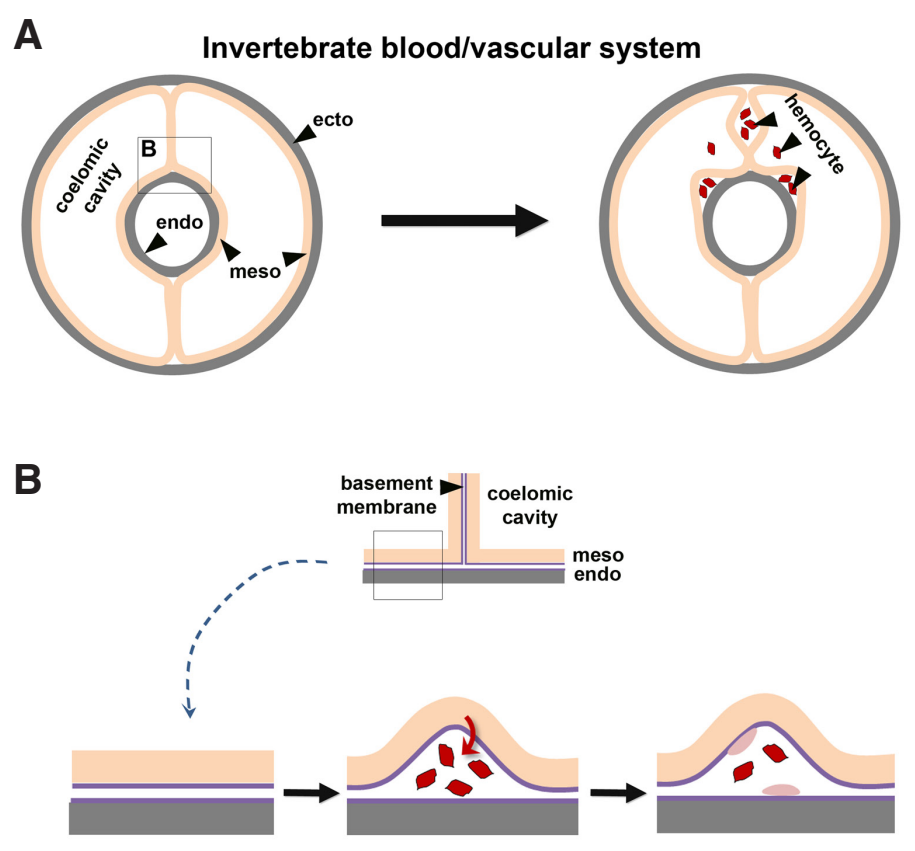

C

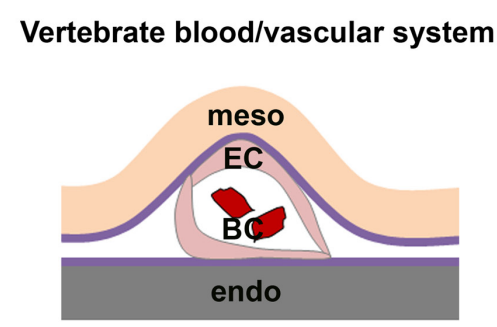

Fig. 3. Relationship between invertebrate and vertebrate blood/vascular systems. (A) Schematic view of how the blood cells (hemocytes) and vascular channels are formed from the coelomic epithelium. Ecto: ectoderm. Meso: mesoderm; mesothelial mesoderm. Endo: endoderm. (B) Magnified view of how coelomic epithelium gives rise to blood cells and vascular channels in invertebrates and how hypothetical endothelial cells in the vertebrate ancestor may be derived from a subpopulation of hemocytes with high basement membrane adhesion and epithelialization properties. (C) Basic organization of vertebrate blood/vascular system. EC: endothelial cells. BC, blood cells. 

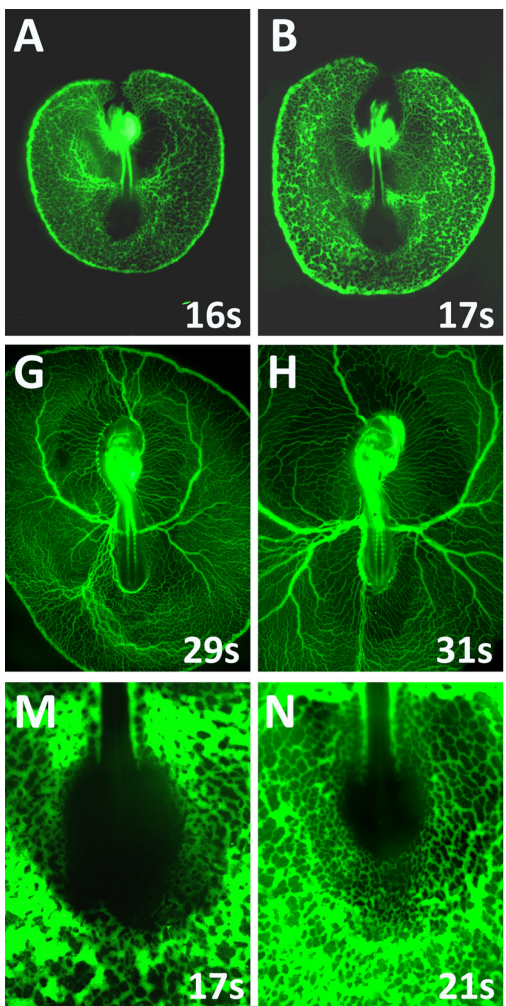
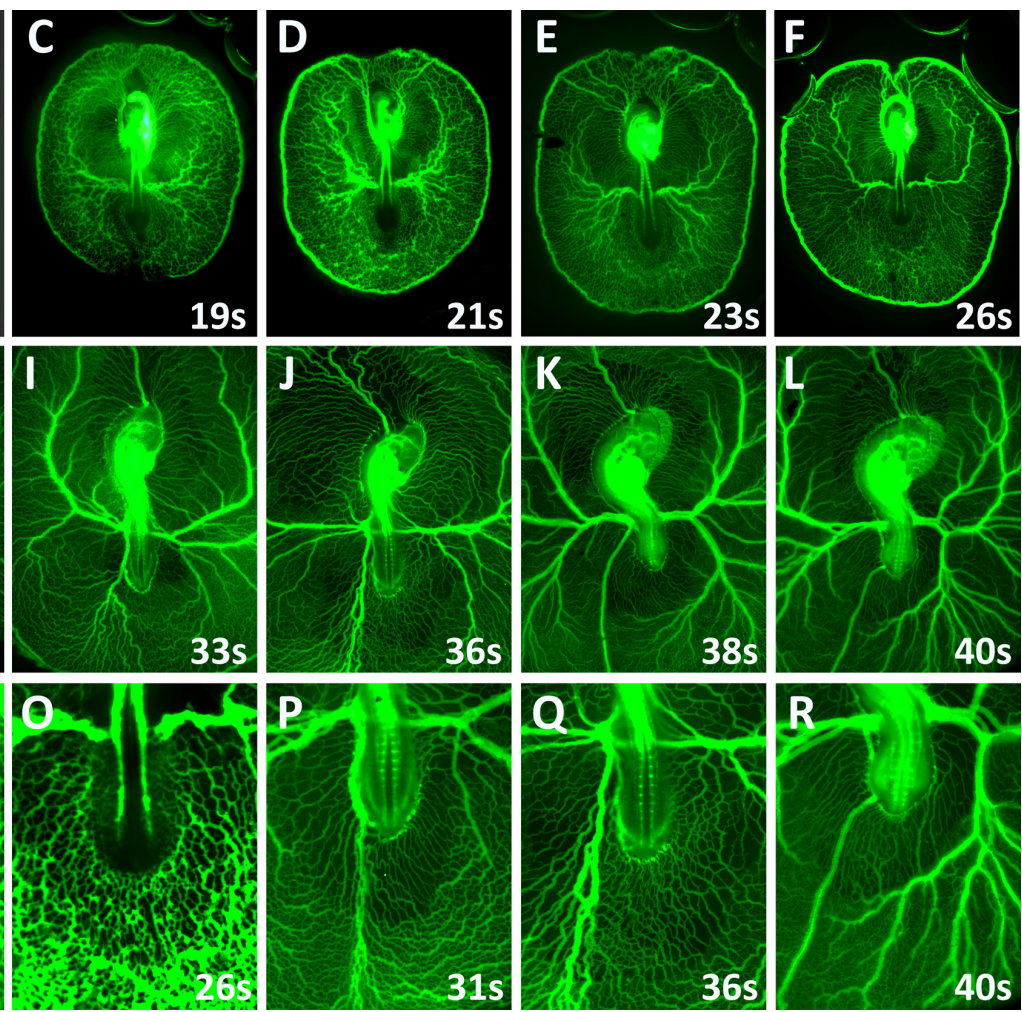

Fig. 4 (above). Establishment of vascular network after circulation. Cardiac function starts from stage HH12. The vascular network was highlighted by injecting a small volume of fluorescein-labeled dextran (500 kDalton) into the heart. Images were taken within one minute after injection. (A-L) Embryo stages are marked by their somite numbers. The contrast was adjusted to show the dynamic changes in the extraembryonic vascular network. Higher magnification views for some of these embryos (marked by somite numbers) are shown in panels (M-R).

\section{2-dimensional vascular network (at D2)}
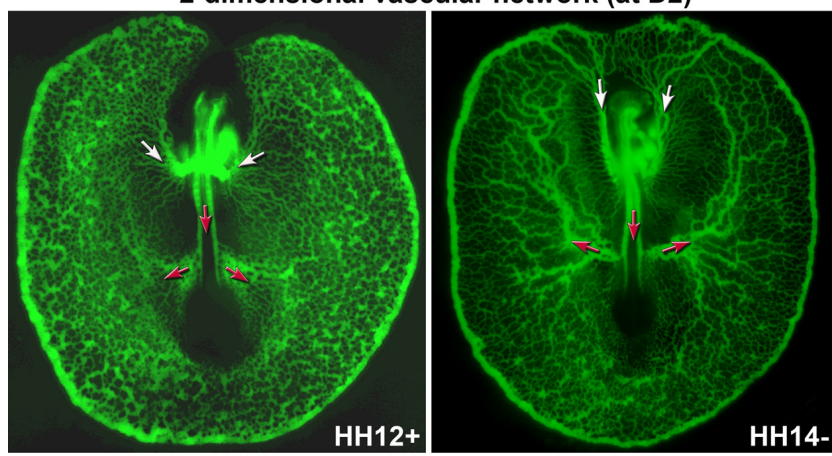

3-dimensional vascular network (at D3)
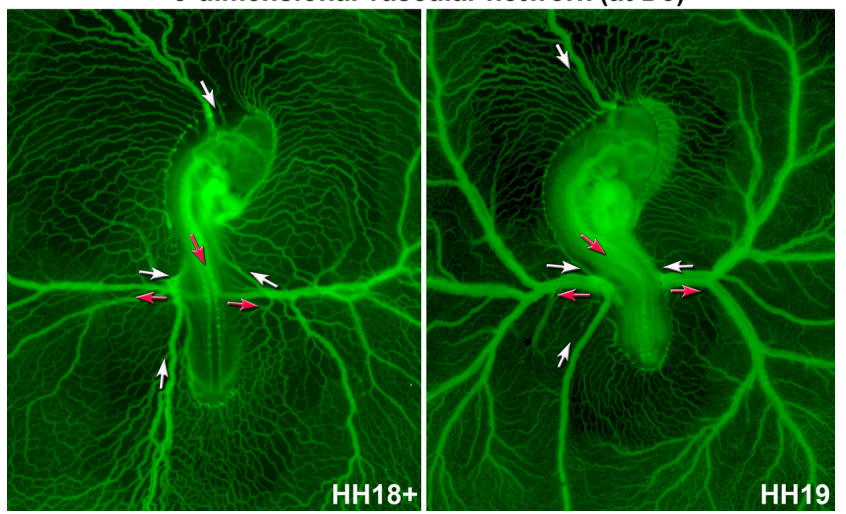

is considered to take place after stage $\mathrm{HH} 7$. Endothelial-shaped cells can be distinguished from stage $\mathrm{HH} 8$ onward. Between stage $\mathrm{HH} 8$ and stage $\mathrm{HH} 11$, driven by morphological changes in differentiating endothelial progenitor cells, a vascular plexus is formed as the result of extensive endothelial lumen formation and anastomosis. This process does not require cardiac function, but involves dynamic movement of vascular endothelial cells within the forming vascular plexus (Sato et al., 2010). Specification of arterial and venous branches within this newly formed vascular network, however, is regulated by cardiac activity-driven blood flow from stage HH12/13 onward (le Noble et al., 2004). Although early hematopoiesis takes place only in the extraembryonic territory, early vasculogenesis covers the entire developing embryo, including both the future embryonic and extraembryonic territories, with no clear morphological or molecular boundaries separating these two regions (Fig. 2A). The posterior, stem zone of the embryo is poorly vascularized in the first day of post-circulation development (from stage $\mathrm{HH} 12$ to stage $\mathrm{HH} 16$ ), after which this region is also fully vascularized (Fig. 4). The direction of blood flow is determined by hemodynamics and is highly susceptible to experimental perturbation, e.g., through extraembryonic vessel ligation. (le Noble et

Fig. 5. Arterial and venous branches of the nascent vascular network. The top two panels show the vascular network by the end of Day 2, soon after the initiation of cardiac function. The bottom two panels show the vascular network approximately one day later. White arrows: yolk sac (vitelline) veins. Red arrows: yolk sac (vitelline) arteries and the dorsal aorta. 
al., 2004). Under normal developmental conditions, however, the extraembryonic vascular tree varies only slightly from embryo to embryo and a conserved flow pattern always emerges (heart $\rightarrow$ dorsal aorta $\rightarrow$ vitelline arteries $\rightarrow$ vitelline veins $\rightarrow$ heart) (Fig. 5). The extraembryonic vascular tree is initially distributed in a twodimensional fashion (Fig. 5, top panels). But within one day, it is quickly remodeled into a complex three-dimensional architecture (Fig. 5, bottom panels), with major extraembryonic arteries and veins running side by side and the capillary bed covering the entire extraembryonic surface. The vascular tree established after Day 3 of chicken development (shown in Fig. 5, bottom panels) is relatively stable, with only minor modifications in sizes of major vessels and with some pruning of minor vessels.

\section{Overview of definitive hematopoiesis in the context of vascular development}

The first wave of chicken hematopoiesis as described earlier in this review produces predominantly the primitive RBCs (Minko et al., 2003, Nakazawa et al., 2006), together with a minor population of macrophage cells (Balic et al., 2014, Cuadros et al., 1993). These primitive RBCs will stay as the major blood cell population until Day 7 of chicken development, after which the definitive RBCs expressing definitive hemoglobin genes become the dominant blood cells (Alev et al., 2008, Nagai and Sheng, 2008). However, definitive hematopoiesis itself is initiated much earlier, during the establishment of a stable vascular network at Day 3. This process is associated with two separate vascular structures. In the intra-embryonic territory, hematopoietic clusters expressing Scl, Lmo2, and Runx1 start to appear on the ventral wall of the dorsal aorta at Day 3 or earlier (Dieterlen-Lievre et al., 2006, Jaffredo et al., 2003, Jaffredo et al., 2005, Jaffredo et al., 2000, Jaffredo et al., 1998, Yvernogeau and Robin, 2017). These cells are considered to be the equivalent of definitive hematopoietic stem cells reported in the mouse and zebrafish. Slightly later, in the yolk sac vasculature, a large number of hematopoietic foci appear in situ at Day 4 and become erythropoietic at Day 4.5, expressing definitive-type hemoglobin genes (Nagai and Sheng, 2008). Definitive RBCs enter the circulation from the yolk sac from Day 5 and these cells become

Fig. 6. Transcriptome resource for chicken hematopoietic/vascular study. (A) Schematic diagram depicting embryonic tissues subjected to Affymetrix gene-chip based transcriptome analysis. Two screens, reported previously, compare ventral mesoderm precursors with more dorsal mesoderm lineages (streak areas marked by $A, B, C$ and $D$; with $A$ being the dorsal-most and $D$ being the ventral-most) and as a temporal progression during blood/ vascular development (stages HH4-9). (B) Transcriptome data are visualized via eXintegrator, a tool designed for analyzing gene arraybased transcriptome data (http://martin.jakt.org.uk/work_related/ exint_web/index.html). Three genes are highlighted here. cxcl14 is highly expressed in posterior streak at stage HH4, but low in migrating ventral mesoderm cells. Imo2 is not expressed in the streak, but becomes progressively stronger in ventral mesoderm cells. pi globin is absent before stage HH7 and its expression level rises very rapidly afterwards. EE, extraembryonic; PS, primitive streak; $R B C$, red blood cell.

\section{A}

dominant RBCs at Day 7. Dorsal aorta-derived hematopoietic cells do not undergo erythropoietic differentiation in para-aortic foci in the vicinity of dorsal aorta. It is possible that hematopoietic cells generated in the dorsal aorta contribute to the yolk sac definitive erythropoiesis between Day 4 and Day 12. From about Day 12 of chick development, the bone marrow niche matures and takes over the yolk sac as the major location of hematopoietic activities, remaining so during the last third of embryonic development and after hatching (Sheng, 2010). The composition and origin of definitive hematopoietic stem cells taking up the bone marrow niche, i.e., whether they are derived from the dorsal-aorta or the yolk sac and what their relative contributions are, are not clear.

\section{Transcriptomics and promoteromics resources for studying early blood/vascular development}

With easy accessibility, the field of hematopoietic and cardiovascular research owes its origin to the chick model. The chick

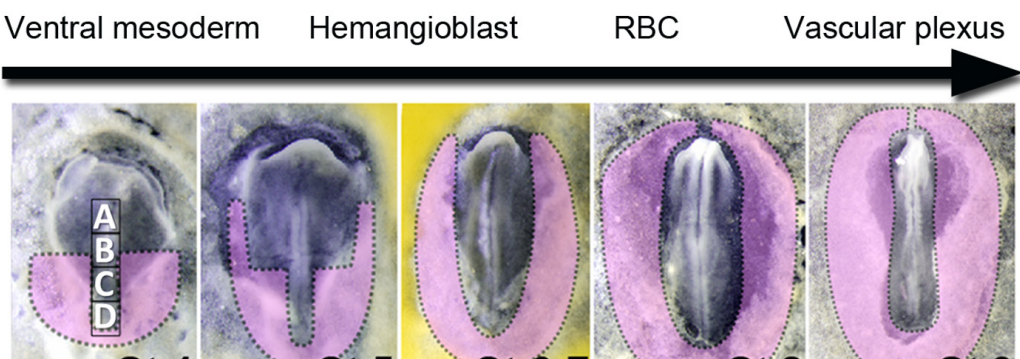
$\begin{array}{llllll}\text { St.4 } & \text { St.5 } & \text { St.6-7 } & \text { St.8 } & \text { St.9 }\end{array}$
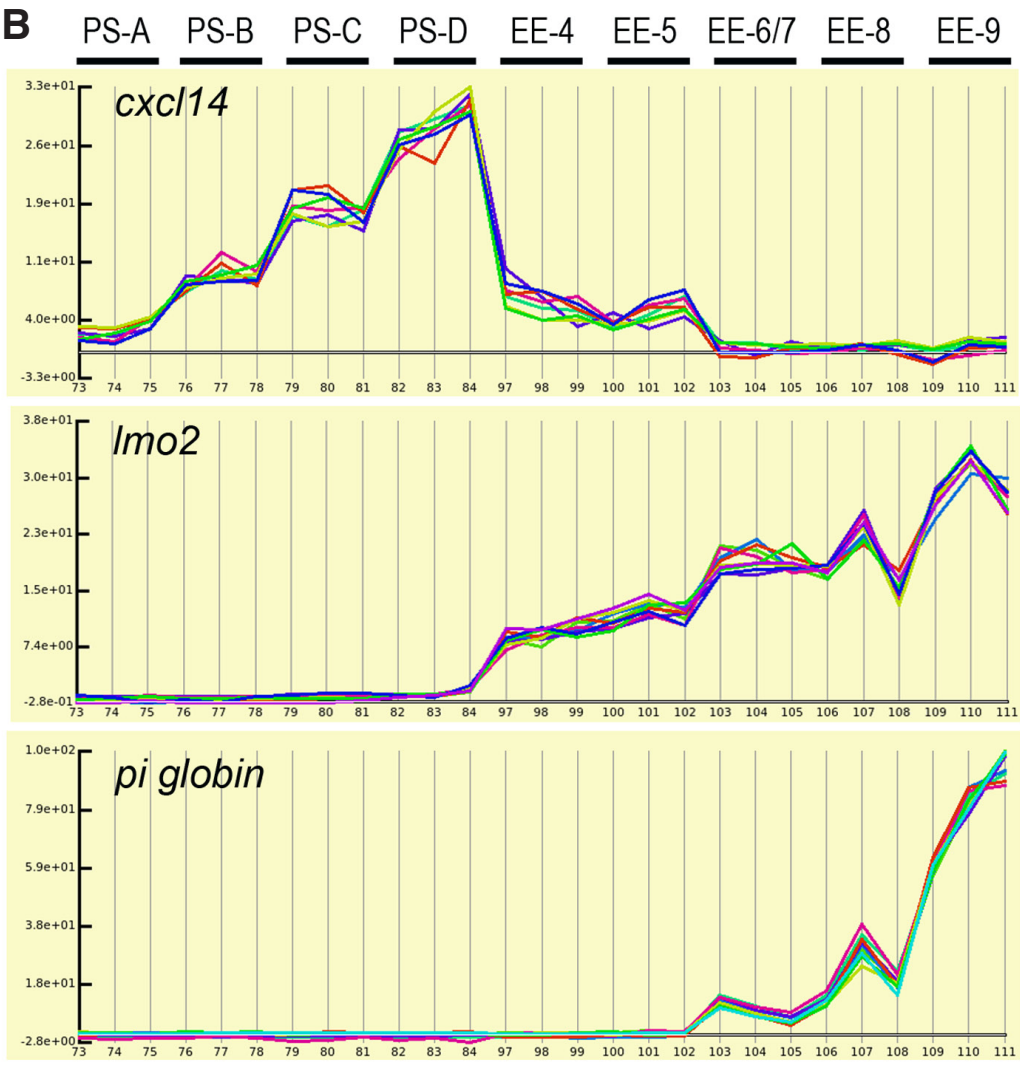

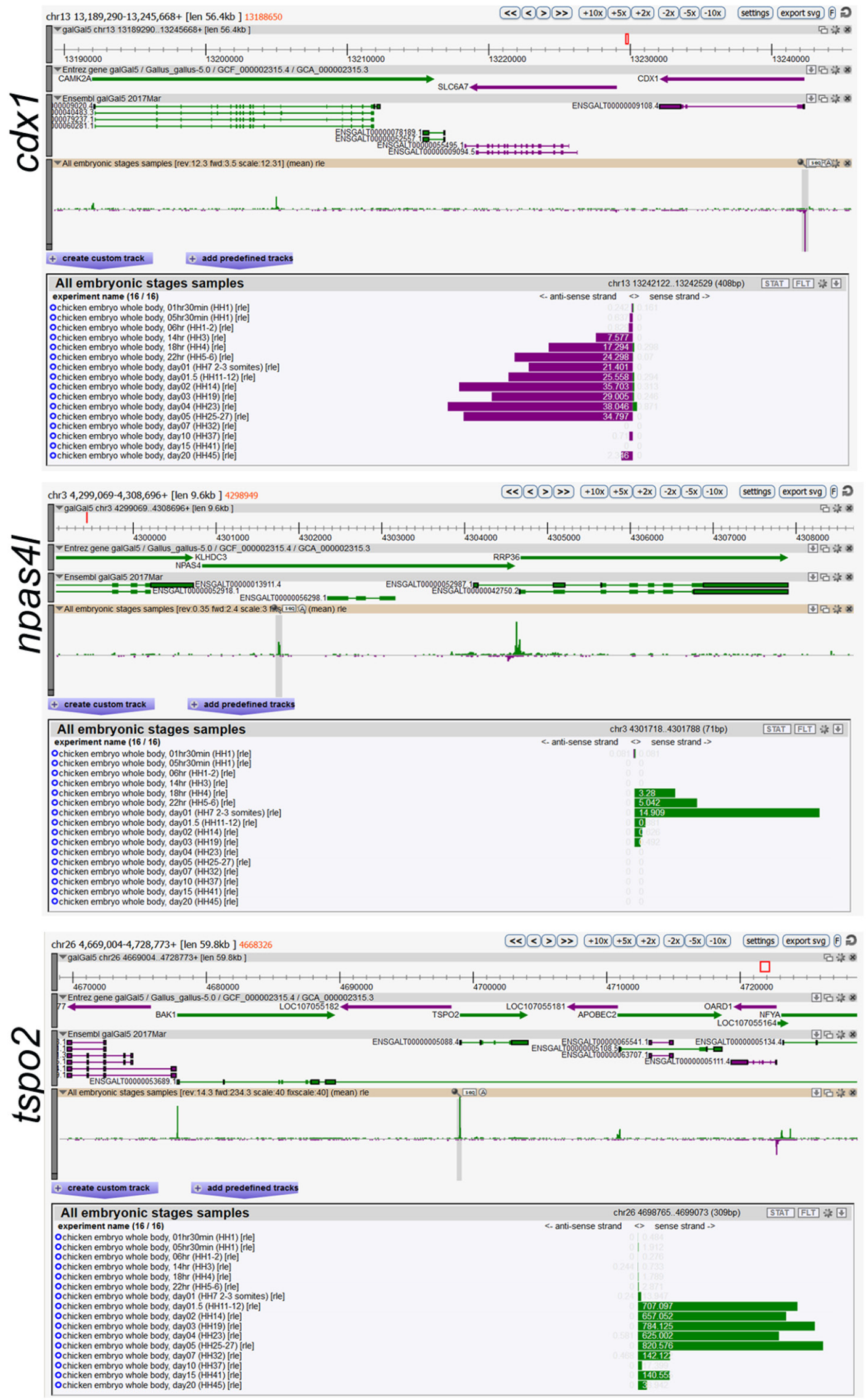

also occupies an important phylogenetic position in vertebrate evolution and serves as an essential intermediate for understanding conservation and diversification in hematopoietic/vascular regulation. Highlighting its continuing importance, the chick model is better suited for omics-scale analysis of hematopoietic/vascular development than other models. For instance, high spatiotemporal resolutions during chick early hematopoietic development allowed us to gain a transcriptome level understanding through genechip based high throughput analyses (Fig. 6A) (Alev et al., 2010b, Nakazawa et al., 2009). Such analysis has not been feasible with other models until very recently when single-cell transcriptomics has obscured technical barriers traditionally known for model organisms (Peng et al., 2016, Satija et al., 2015, Scialdone et al., 2016). Data from these transcriptomic analyses let us conclude that most of the key regulatory genes, previously reported to play important roles in early hematopoietic development through genetic studies in the mouse and zebrafish models, are conserved in the chick (e.g. Imo2 shown in Fig. 6B). This concept of general conservation in

Fig. 7. Promoterome resource for chicken hematopoietic/vascular study. CAGE (cap analysis of gene expression) technology is used to pinpoint transcription start sites and their changes for all genes throughout chicken development. Three examples for genes involved in hematopoietic/ vascular developmentare shown. cdx1 is a ventral mesoderm marker. npas4l is the ortholog of zebrafish cloche gene and is a novel candidate for hemangioblast specification in the chick. tspo2 is an erythrocyte specific gene with unclear molecular function. 
hematopoietic/vascular regulation was further supported by data from expression and functional studies for many chicken genes (Alev et al., 2010a, Bollerot et al., 2005, Chervenak et al., 2006, Mclntyre et al., 2008, Minko et al., 2003, Nakazawa et al., 2011, Weng and Sheng, 2014). More recently, extending chicken early developmental investigation to the promoterome-level analysis using CAGE (Cap Analysis of Gene Expression) technology (Fantum Consortium et al., 2014), transcriptional activity and promoter usage of all genes involved in hematopoietic/vascular development could be visualized on an integrated genome browser (Fig. 7) (Lizio et al., 2017), allowing both single base pair-level and genome-level analyses of hematopoiesis regulatory genes simultaneously. Combining this with gene ontology (GO) resources from the mouse, we found that out of a total 225 mouse genes (Sup-Table 1) annotated for transcriptional regulation of hematopoiesis (GO: 0003700 transcription factor activity and GO: 0030097 hematopoiesis; amigo.geneontology.org), 70 (Sup-Table 1, highlighted green) are expressed in the chick embryo between stage $\mathrm{HH} 3$ and stage $\mathrm{HH}$, a developmental window for hemangioblast specification. Most of the known hematopoietic regulators, such as Imo2, scl, ets 1 and gata genes are included among them, suggesting that the remaining, not well-studied genes are suitable candidates for future studies. Interestingly, such comparison also underscores the importance of taking an evolutionary and comparative approach in hematopoietic/vascular research. For example, a homolog of npas4l, the hemangioblast master regulator in the zebrafish (Reischauer et al., 2016), is present in the chicken genome and is expressed during chicken hemangioblast specification (Fig. 7). However, because this gene is lost in the mammalian lineage, our gene ontology based mouse/chick comparison did not reveal the potential involvement of $n$ pas $4 /$ in chicken hematopoietic/vascular development. Functional analyses of this and other similar genes in the future would shed light on the diversification of hematopoietic/ vascular regulation among different vertebrate groups.

\section{References}

ALEV, C., MCINTYRE, B.A., NAGAI, H., SHIN, M., SHINMYOZU, K., JAKT, L.M. and SHENG, G. (2008). BetaA, the major beta globin in definitive red blood cells, is present from the onset of primitive erythropoiesis in chicken. Dev Dyn 237: 1193-1197.

ALEV, C., MCINTYRE, B.A., OTA, K. and SHENG, G. (2010a). Dynamic expression of Endoglin, a TGF-beta co-receptor, during pre-circulation vascular development in chick. Int J Dev Biol 54: 737-742.

ALEV, C., WU, Y., KASUKAWA, T., JAKT, L.M., UEDA, H.R. and SHENG, G. (2010b). Transcriptomic landscape of the primitive streak. Development 137: 2863-2874.

BALIC, A., GARCIA-MORALES, C., VERVELDE, L., GILHOOLEY, H., SHERMAN, A., GARCEAU, V., GUTOWSKA, M.W., BURT, D.W., KAISER, P., HUME, D.A. et al., (2014). Visualisation of chicken macrophages using transgenic reporter genes: insights into the development of the avian macrophage lineage. Development 141: 3255-3265.

BOLLEROT, K., ROMERO, S., DUNON, D. and JAFFREDO, T. (2005). Core binding factor in the early avian embryo: cloning of Cbfbeta and combinatorial expression patterns with Runx1. Gene Expr Patterns 6: 29-39.

CHERVENAK, A.P., BASU, P., SHIN, M., REDMOND, L.C., SHENG, G. and LLOYD, J.A. (2006). Identification, characterization, and expression pattern of the chicken EKLF gene. Dev Dyn 235: 1933-1940.

CUADROS, M.A., MARTIN, C., COLTEY, P., ALMENDROS, A. and NAVASCUES, J. (1993). First appearance, distribution, and origin of macrophages in the early development of the avian central nervous system. J Comp Neuro/ 330: 113-129.

DIETERLEN-LIEVRE, F., POUGET, C., BOLLEROT, K. and JAFFREDO, T. (2006). Are intra-aortic hemopoietic cells derived from endothelial cells during ontogeny?
Trends Cardiovasc Med 16: 128-139.

FANTOM CONSORTIUM and RIKEN PMI and CLST (DGT) (2014). A promoter-level mammalian expression atlas. Nature 507: 462-470.

HARTENSTEIN, V. (2006). Blood cells and blood cell development in the animal kingdom. Annu Rev Cell Dev Biol 22: 677-712.

JAFFREDO, T., ALAIS, S., BOLLEROT, K., DREVON, C., GAUTIER, R., GUEZGUEZ, B., MINKO, K., VIGNERON, P. and DUNON, D. (2003). Avian HSC emergence, migration, and commitment toward the $\mathrm{T}$ cell lineage. FEMS Immunol Med Microbiol 39: 205-212.

JAFFREDO, T., BOLLEROT, K., SUGIYAMA, D., GAUTIER, R. and DREVON, C. (2005). Tracing the hemangioblast during embryogenesis: developmental relationships between endothelial and hematopoietic cells. Int J Dev Biol 49: 269-277.

JAFFREDO, T., GAUTIER, R., BRAJEUL, V. and DIETERLEN-LIEVRE, F. (2000). Tracing the progeny of the aortic hemangioblast in the avian embryo. Dev Biol 224: $204-214$

JAFFREDO, T., GAUTIER, R., EICHMANN, A. and DIETERLEN-LIEVRE, F. (1998). Intraaortic hemopoietic cells are derived from endothelial cells during ontogeny. Development 125: 4575-4583.

KUCERA, T., STRILIC, B., REGENER, K., SCHUBERT, M., LAUDET, V. and LAMMERT, E. (2009). Ancestral vascular lumen formation via basal cell surfaces. PLOS ONE 4: e4132.

LE NOBLE, F., MOYON, D., PARDANAUD, L., YUAN, L., DJONOV, V., MATTHIJSEN, R., BREANT, C., FLEURY, V. and EICHMANN, A. (2004). Flow regulates arterialvenous differentiation in the chick embryo yolk sac. Development 131: 361-375.

LIZIO, M., DEVIATIIAROV, R., NAGAI, H., GALAN, L., ARNER, E., ITOH, M., LASSMANN, T., KASUKAWA, T., HASEGAWA, A., ROS, M.A. et al., (2017). Systematic analysis of transcription start sites in avian development. PLoS Biol 15: e2002887.

MARTINSEN, B.J. (2005). Reference guide to the stages of chick heart embryology. Dev Dyn 233: 1217-1237.

MCINTYRE, B.A., ALEV, C., TARUI, H., JAKT, L.M. and SHENG, G. (2008). Expression profiling of circulating non-red blood cells in embryonic blood. BMC Dev Bio/8:21.

MINKO, K., BOLLEROT, K., DREVON, C., HALLAIS, M.F. and JAFFREDO, T. (2003). From mesoderm to blood islands: patterns of key molecules during yolk sac erythropoiesis. Gene Expr Patterns 3: 261-272.

MONAHAN-EARLEY, R., DVORAK, A.M. andAIRD, W.C. (2013). Evolutionary origins of the blood vascular system and endothelium. J Thromb Haemost 11 Suppl 1:46-66.

MUNOZ-CHAPULI, R., CARMONA, R., GUADIX, J.A., MACIAS, D. and PEREZPOMARES, J.M. (2005). The origin of the endothelial cells: an evo-devo approach for the invertebrate/vertebrate transition of the circulatory system. Evol Dev 7: 351-358

NAGAI, H. and SHENG, G. (2008). Definitive erythropoiesis in chicken yolk sac. Dev. Dyn. 237: 3332-3341.

NAKAYA, Y. and SHENG, G. (2009). An amicable separation: Chick's way of doing EMT. Cell Adh Migr 3: 160-163.

NAKAYA, Y., SUKOWATI, E.W. and SHENG, G. (2013). Epiblast integrity requires CLASP and Dystroglycan-mediated microtubule anchoring to the basal cortex. J Cell Biol 202: 637-651.

NAKAZAWA, F., ALEV, C., JAKT, L.M. and SHENG, G. (2011). Yolk sac endoderm is the major source of serum proteins and lipids and is involved in the regulation of vascular integrity in early chick development. Dev Dyn 240: 2002-2010.

NAKAZAWA, F., ALEV, C., SHIN, M., NAKAYA, Y., JAKT, L.M. and SHENG, G. (2009). $\mathrm{PBRL}$, a putative peripheral benzodiazepine receptor, in primitive erythropoiesis. Gene Expr Patterns 9: 114-121.

NAKAZAWA, F., NAGAI, H., SHIN, M. and SHENG, G. (2006). Negative regulation of primitive hematopoiesis by the FGF signaling pathway. Blood 108: 3335-3343.

PENG, G., SUO, S., CHEN, J., CHEN, W., LIU, C., YU, F., WANG, R., CHEN, S., SUN, N., CUI, G. et al., (2016). Spatial Transcriptome for the Molecular Annotation of Lineage Fates and Cell Identity in Mid-gastrula Mouse Embryo. Dev Cell 36: 681-697.

PSYCHOYOS, D. and STERN, C.D. (1996). Fates and migratory routes of primitive streak cells in the chick embryo. Development 122: 1523-1534.

REISCHAUER, S., STONE, O.A., VILLASENOR, A., CHI, N., JIN, S.W., MARTIN M., LEE, M.T., FUKUDA, N., MARASS, M., WITTY, A. et al., (2016). Cloche is a bHLH-PAS transcription factor that drives haemato-vascular specification. Nature 535: 294-298. 


\section{H. Nagai et al.}

SATIJA, R., FARRELL, J.A., GENNERT, D., SCHIER, A.F. and REGEV, A. (2015). Spatial reconstruction of single-cell gene expression data. Nat Biotechnol 33: 495-502.

SATO, Y., POYNTER, G., HUSS, D., FILLA, M.B., CZIROK, A., RONGISH, B.J., LITTLE, C.D., FRASER, S.E. and LANSFORD, R. (2010). Dynamic analysis of vascular morphogenesis using transgenic quail embryos. PLOS ONE 5: e12674.

SCIALDONE, A., TANAKA, Y., JAWAID, W., MOIGNARD, V., WILSON, N.K., MACAULAY, I.C., MARIONI, J.C. and GOTTGENS, B. (2016). Resolving early mesoderm diversification through single-cell expression profiling. Nature 535: 289-293.

SHENG, G. (2010). Primitive and definitive erythropoiesis in the yolk sac: a bird's eye view. Int J Dev Biol 54: 1033-1043.

SHIN, M., NAGAI, H. and SHENG, G. (2009). Notch mediates Wnt and BMP signals in the early separation of smooth muscle progenitors and blood/endothelial common progenitors. Development 136: 595-603.

WENG, W. and SHENG, G. (2014). Five transcription factors and FGF pathway inhibition efficiently induce erythroid differentiation in the epiblast. Stem Cell Reports 2: 262-270.

WENG, W., SUKOWATI, E.W. and SHENG, G. (2007). On hemangioblasts in chicken PLOS ONE 2: e1228.

YANG, X., CHRISMAN, H. and WEIJER, C.J. (2008). PDGF signalling controls the migration of mesoderm cells during chick gastrulation by regulating $\mathrm{N}$-cadherin expression. Development 135: 3521-3530.

YVERNOGEAU, L. and ROBIN, C. (2017). Restricted intra-embryonic origin of bona fide hematopoietic stem cells in the chicken. Development 144: 2352-2363. 


\section{Further Related Reading, published previously in the Int. J. Dev. Biol.}

Disruption of the aortic wall by coelomic lining-derived mesenchymal cells accompanies the onset of aortic hematopoiesis Alaa A. Arraf, Marella F.T.R. De Bruijn and Thomas M. Schultheiss

Int. J. Dev. Biol. (2017) 61: 329-335

https://doi.org/10.1387/ijdb.170012ts

The Leo Sachs' legacy: a pioneer's journey through hematopoiesis

Joseph Lotem and Yoram Groner

Int. J. Dev. Biol. (2017) 61: 127-136

https://doi.org/10.1387/ijdb.160262yg

Hippo signaling components, Mst1 and Mst2, act as a switch between self-renewal and differentiation in Xenopus hematopoietic and endothelial progenitors

Susumu Nejigane, Shuji Takahashi, Yoshikazu Haramoto, Tatsuo Michiue and Makoto Asashima Int. J. Dev. Biol. (2013) 57: 407-414

https://doi.org/10.1387/ijdb.130010st

Gene regulatory networks governing haematopoietic stem cell development and identity John E. Pimanda and Berthold Göttgens

Int. J. Dev. Biol. (2010) 54: 1201-1211

https://doi.org/10.1387/ijdb.093038jp

The Notch pathway in the developing hematopoietic system

Anna Bigas, Àlex Robert-Moreno and Lluís Espinosa

Int. J. Dev. Biol. (2010) 54: 1175-1188

https://doi.org/10.1387/ijdb.093049ab

Definitive human and mouse hematopoiesis originates from the embryonic endothelium: a new class of HSCs based on VE-cadherin expression

Estelle Oberlin, Bouchra El Hafny, Laurence Petit-Cocault and Michèle Souyri

Int. J. Dev. Biol. (2010) 54: 1165-1173

https://doi.org/10.1387/ijdb.103121eo

5 yr ISI Impact Factor $(2016)=2.421$

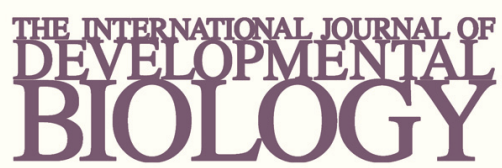

Volume 54 Nos. 6/7

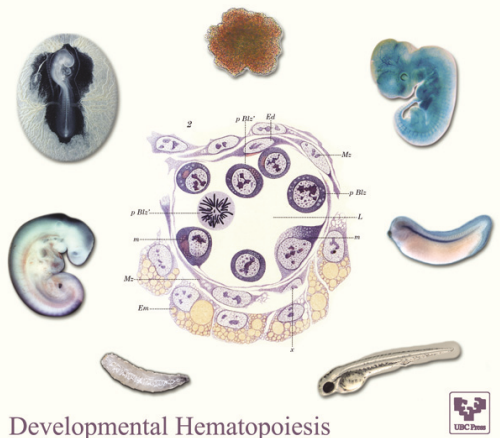

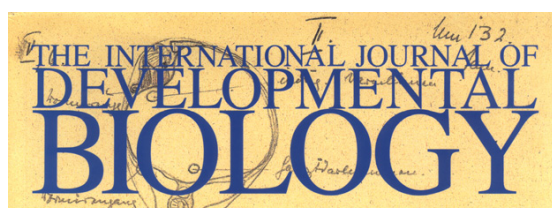

Volume 45 No. 1
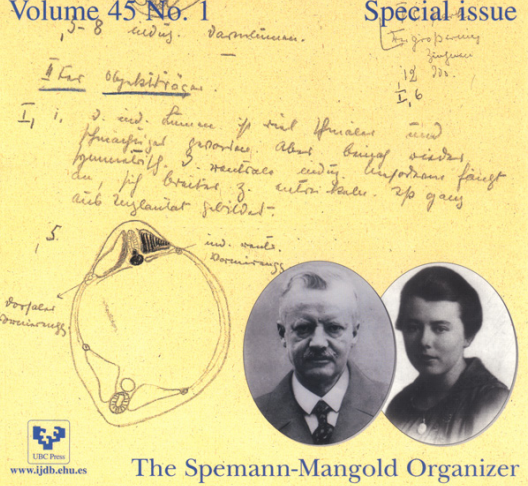
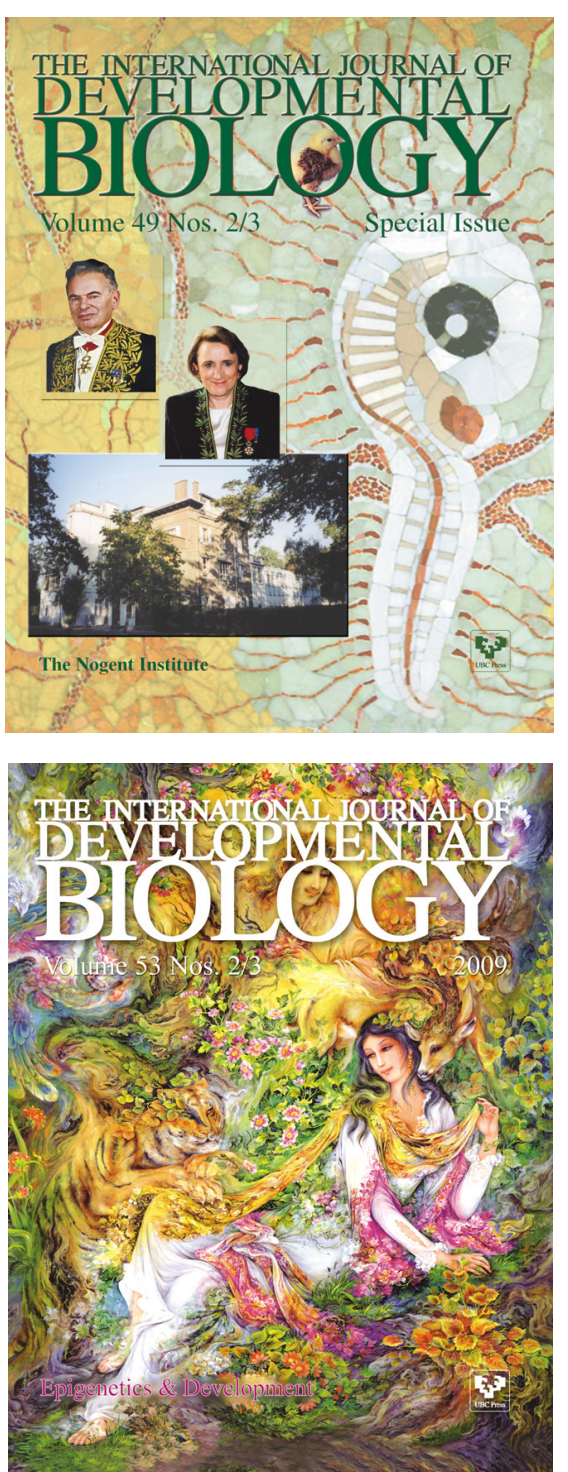